\title{
Endoscopic treatment of congenital tracheoesophageal fistula using submucosal resection and closure by clip
}

\author{
Chang-hua He MD¹, Qing Zhang $M D^{2}$, Mei Liu MD², Wei-zheng Wang MD¹, \\ An-hua Xiao BSc${ }^{1}$, Xu-yan Zuo BSc ${ }^{1}$, Yan Zhou BSc ${ }^{1}$
}

\begin{abstract}
Congenital tracheoesophageal fistula (TEF) without esophageal
atresia (H-type) is a rare condition in adult patients (1). TEF presents in the form of frequent respiratory infections, coughing episodes when eating or drinking, paroxysmal cough and hemoptysis. Surgical repair with thoracotomy is the standard management for TEF (2). Endoscopic repair of TEF is an effective and safe alternative to repeat thoracotomy and open surgical repair (3). More than one endoscopic procedure is usually necessary for successful closure. The present report describes a transesophageal technique for endoscopic submucosal resection and clip occlusion of $\mathrm{H}$-type TEF in an adult. We suggest this approach as an alternative method for treating TEF.
\end{abstract}

\section{CASE PRESENTATION}

A 45-year-old man was admitted to hospital with complaints of recurrent cough and choking after swallowing liquid since childhood, especially in the standing position. His symptoms had been previously ascribed to chronic bronchitis and lung infections; antibiotics resulted
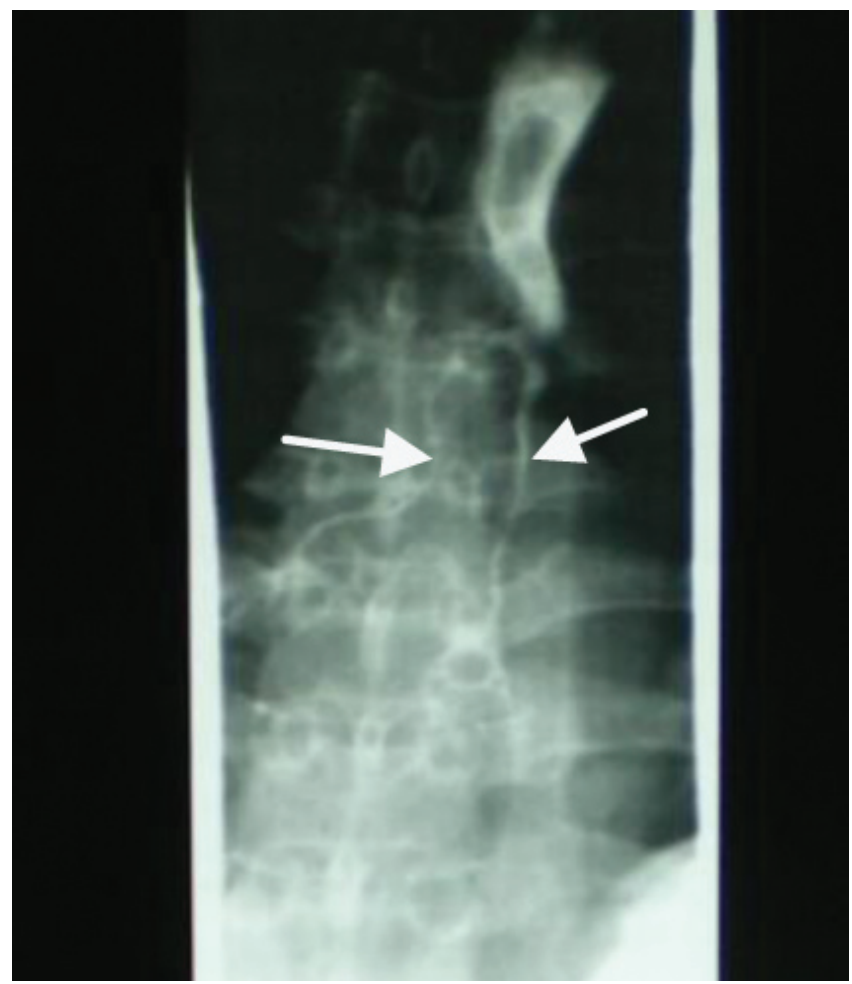

Figure 1) A barium esophagogram revealing a fistula between the lower esophageal and segmental bronchus of the right lower lung field (arrows) in improvement, but the symptoms still recurred. A series of in-hospital examinations produced a diagnosis of TEF. A barium esophagogram revealed a fistula between the lower esophageal and segmental bronchus of the right lower right lung field (Figure 1). A computed tomography (CT) scan of his chest revealed TEF and infection in the lower right lung. A repeat CT scan performed after the patient was given lohexol contrast media showed the fistula more clearly. Subsequently, TEF was confirmed by upper gastrointestinal endoscopy, which revealed a diverticulum (approximately $6 \mathrm{~mm}$ in diameter) in the lower esophagus (Figure 2A). There were two holes (approximately $2 \mathrm{~mm}$ in diameter) in the bottom of the diverticulum (Figure 2B).

Because the patient declined surgery, and the diverticulum and fistulas were small, it was decided to attempt endoscopicTEF closure. An approach with endoscopic submucosal resection and closure by clip for endoscopic repair of TEF was proposed. Following a lengthy discussion

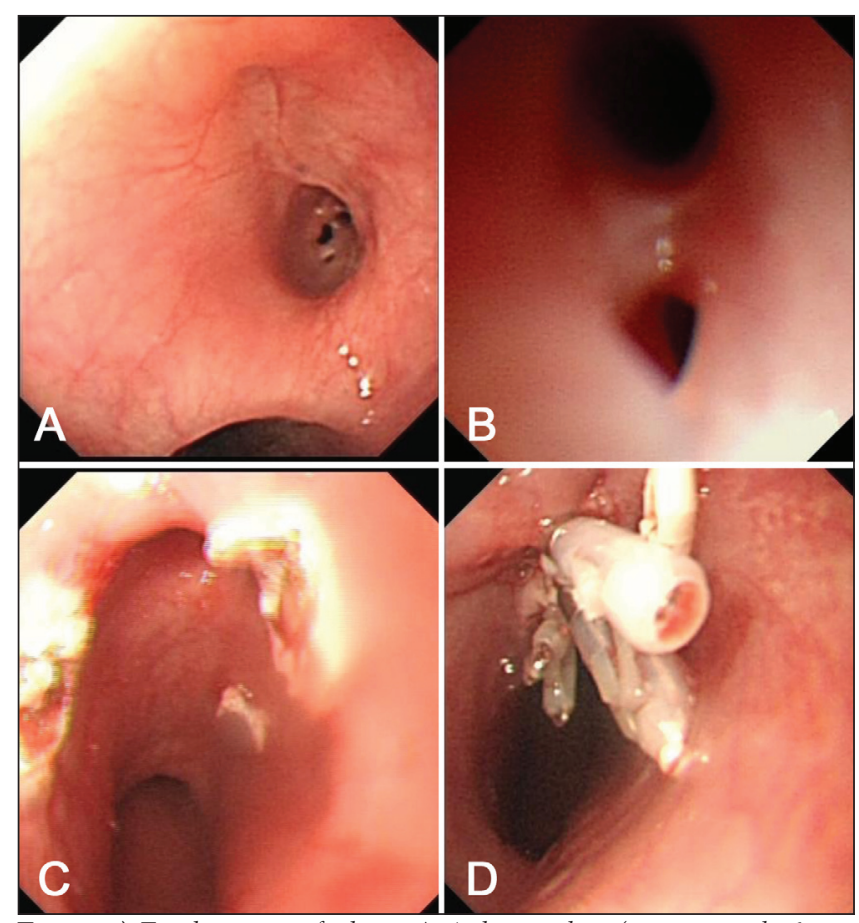

Figure 2) Esophagoscopic findings. A A diverticulum (approximately $6 \mathrm{~mm}$ in diameter) in the lower esophagus. B Two fistulas in the bottom of the diverticulum. C Symmetrical artificial wounds were made in the anterior and posterior walls of the diverticular opening. D The diverticulum was clipped

${ }^{1}$ Department of Gastroenterology, No 1 Hospital Affiliated to Yangtze University; ${ }^{2}$ Department of Internal Medicine, Clinical Medical College of Yangtze University, Jingzhou of Hubei; ${ }^{3}$ Department of Gastroenterology, Tongji Hospital Affiliated to Tongii Medical college, Huazhong University of Science and Technology, Wuhan, Hubei Province, China

Correspondence: Dr Qing Zhang, Department of Internal Medicine, Clinical Medical College of Yangtze University, Jingzhou of Hubei, 434000, China.

E-mailwww95@126.com

Received for publication December 17, 2011. Accepted December 20, 2011 
that detailed risks, feasibility and alternatives, the following procedure was performed. With the patient under anesthesia, an upper gastrointestinal endoscope (GIF XQ260 [Olympus Optical Co, Ltd, Japan]) was retroflexed in the esophagus. The diverticulum with two fistulas was visualized. The anterior and posterior wall of the diverticular opening were injected with approximately $10 \mathrm{~mL}$ of normal saline using a submucosal needle. A high-frequency electrosurgical snare (Microvasive Endoscopy, Boston Scientific Corporation, USA) was placed along the elevated esophageal mucosa by injection and tightened, and resection was performed by using a blended electrosurgical current (UES-30 generator [Olympus Olympus Optical Co, Ltd, Japan], set at approximately $40 \mathrm{~W}$ to $60 \mathrm{~W}$ output). Symmetrical wounds were made artificially in the anterior and posterior wall of the diverticular opening (Figure 2C). In the final step, the fistulas were closed with clips that clamped both wounds (Figure 2D). Following the procedure, the patient's choking disappeared completely and his cough improved. Two weeks later, his cough disappeared. After six months, a repeat endoscopy showed complete closure of the fistula and normal esophageal mucosa without diverticula or fistula.

\section{DISCUSSION}

Congenital TEF without esophageal atresia (ie, H-type TEF) accounts for approximately $4 \%$ of esophageal malformations (1). The symptoms are usually insidious and not severe; therefore, TEF is occasionally diagnosed after adolescence - congenital TEF is a rare diagnosis in adults. The diagnosis is established using bronchoscopy, esophagoscopy, barium swallow and CT scan (4). In addition to these examinations, and to more clearly define the TEF, we innovatively used a chest CT scan with contrast media.

Surgery is indicated for symptom control, and to prevent and treat TEF-associated pulmonary sepsis; however, the surgery may cause more wounds and is more expensive. There are several reports regarding endoscopic repair of TEF. Yoon et al (5) proposed endoscopic treatment of recurrent congenital TEF with histoacryl glue; however, endoscopic technicians must be highly experienced, otherwise, the endoscope can be easily damaged by the histoacryl glue. Furthermore, after endoscopic treatment with histoacryl glue, the glue may dislodge. We did not use histoacryl glue in this patient because of the concerm that dislodged glue could lead to embolism. Mathew et al (6) proposed endoscopic treatment in the form of submucosal dissection and isolation of congenital TEF - a therapeutic technique involving tunnel endoscopy. The method can effectively close fistulas, but the procedure is very complicated, takes longer to perform and may increase patient discomfort. The TEF in our patient was unique in that the fistulas were located at the base of the esophageal diverticulum. Because the diverticulum of the esophagus in this patient was small, and accounting for therapeutic efficacy and attempts to minimize his discomfort, we proposed an endoscopic approach with endoscopic submucosal resection and closure by clip for repair of the TEF. The entire procedure took approximately $10 \mathrm{~min}$ to perform and successfully closed the patient's TEF.

Natural orifice transluminal endoscopic surgery has gradually replaced traditional surgery due to its many advantages, such as decreased neurohumoral stress response, decreased immunosuppression, less pain, faster recovery and a decreased incidence of woundrelated and pulmonary complications $(7-10)$. It is very important to consider simple methods when trying to solve complex problems - a concept that is also useful in the treatment of disease. Endoscopic management of TEF is both safe and effective, and will eventually replace traditional surgery. The method of endoscopic submucosal resection and closure by clip for endoscopic repair of TEF was demonstrated to be an effective treatment in this patient. As a result, we suggest this approach as an alternative method for treating TEF because it may result in a good outcome.

\section{REFERENCES}

1. Brookes JT, Smith MC, Smith RJ, Bauman NM, Manaligod JM, Sandler AD. H-type congenital tracheoesophageal fistula: University Of Iowa experience 1985 to 2005.

Ann Otol Rhinol Laryngol 2007;116:363-8.

2. Kovesi T, Rubin S. Long-term complications of congenital esophageal atresia and/or tracheoesophageal fistula. Chest 2004;126:915-25.

3. Meier JD, Sulman CG, Almond PS, Holinger LD. Endoscopic management of recurrent congenital tracheoesophageal fistula: A review of techniques and results.

Int J Pediatr Otorhinolaryngol 2007;71:691-7.

4. Beasley SW, Myers NA. The diagnosis of congenital tracheoesophageal fistula. J Pediatr Surg 1988;23:415-7.

5. Yoon JH, Lee HL, Lee OY, et al. Endoscopic treatment of recurrent congenital tracheoesophageal fistula with Histoacryl glue via the esophagus. Gastrointest Endosc 2009;69:1394-6.

6. Mathew A, Moyer M, Yeasted NJ. Submucosal dissection and isolation of a congenital tracheoesophageal fistula for potential endoscopic therapy (with video). Gastrointest Endosc 2009;70:806-9.

7. Voermans RP, Van Berge Henegouwen MI, Fockens P. Natural orifice transluminal endoscopic surgery (NOTES). Endoscopy 2007;39:1013-7.

8. Buyske J. Natural orifice transluminal endoscopic surgery. JAMA 2007;298:1560-1.

9. Kalloo AN. Natural orifice transluminal endoscopic surgery (NOTES). Gastroenterol Hepatol (NY) 2007;3:183-4.

10. Swanstrom LL, Khajanchee Y, Abbas MA. Natural orifice transluminal endoscopic surgery: The future of gastrointestinal surgery. Perm J 2008;12:42-7.

The Canadian Journal of Gastroenterology is now considering a limited number of submissions for IMAGE OF THE MONTH. These are based on endoscopic, histological, radiological and/or patient images, which must be anonymous with no identifying features visible. The patient must consent to publication and the consent must be submitted with the manuscript. All manuscripts should be practical and relevant to clinical practice, and not simply a case report of an esoteric condition. The text should be brief, structured as CASE PRESENTATION and DISCUSSION, and not more than 700 words in length. A maximum of three images can be submitted and the number of references should not exceed five. The submission may be edited by our editorial team.

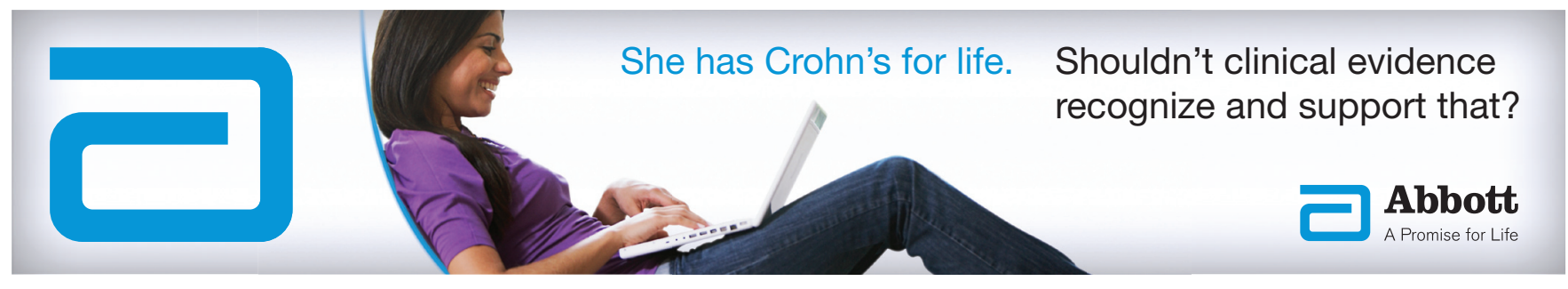




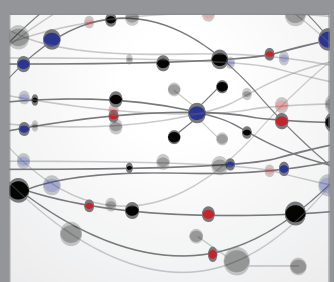

The Scientific World Journal
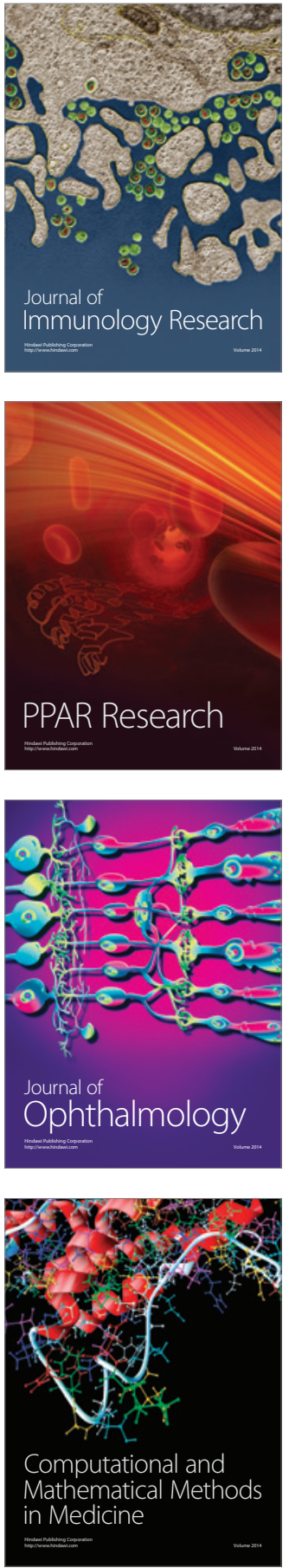

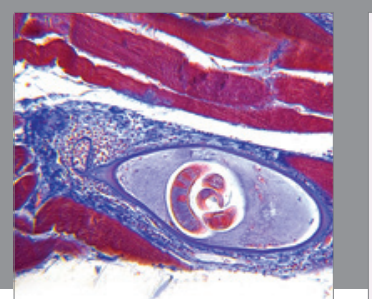

Gastroenterology Research and Practice

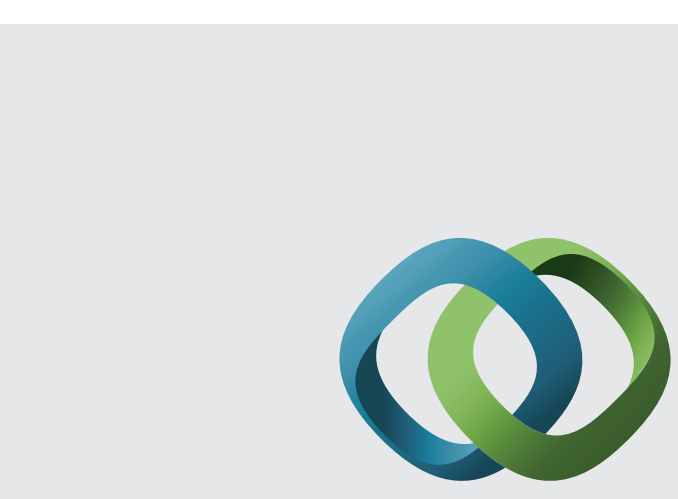

\section{Hindawi}

Submit your manuscripts at

http://www.hindawi.com
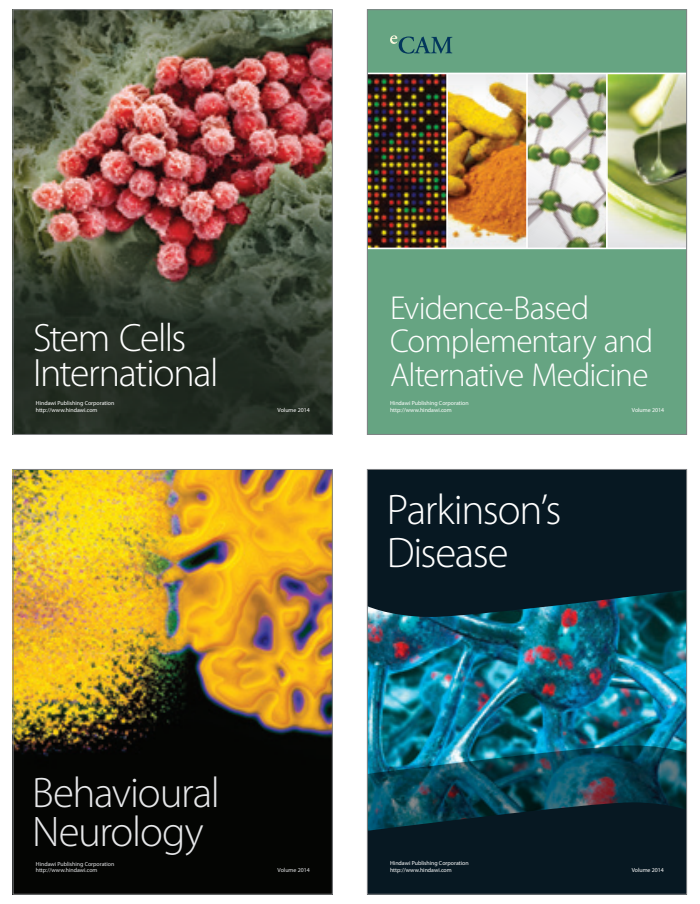
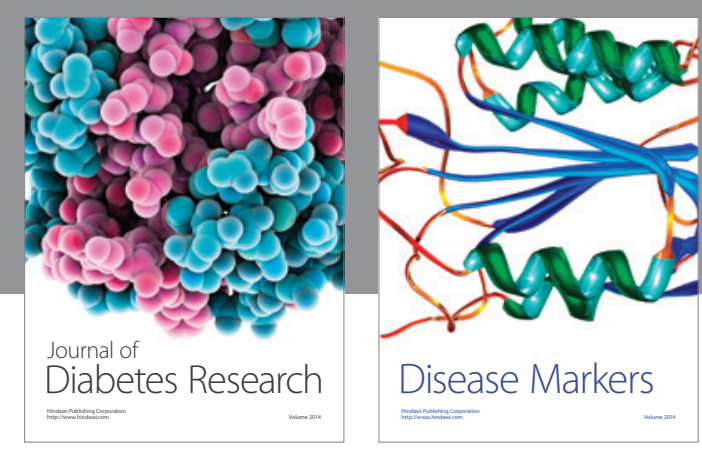

Disease Markers
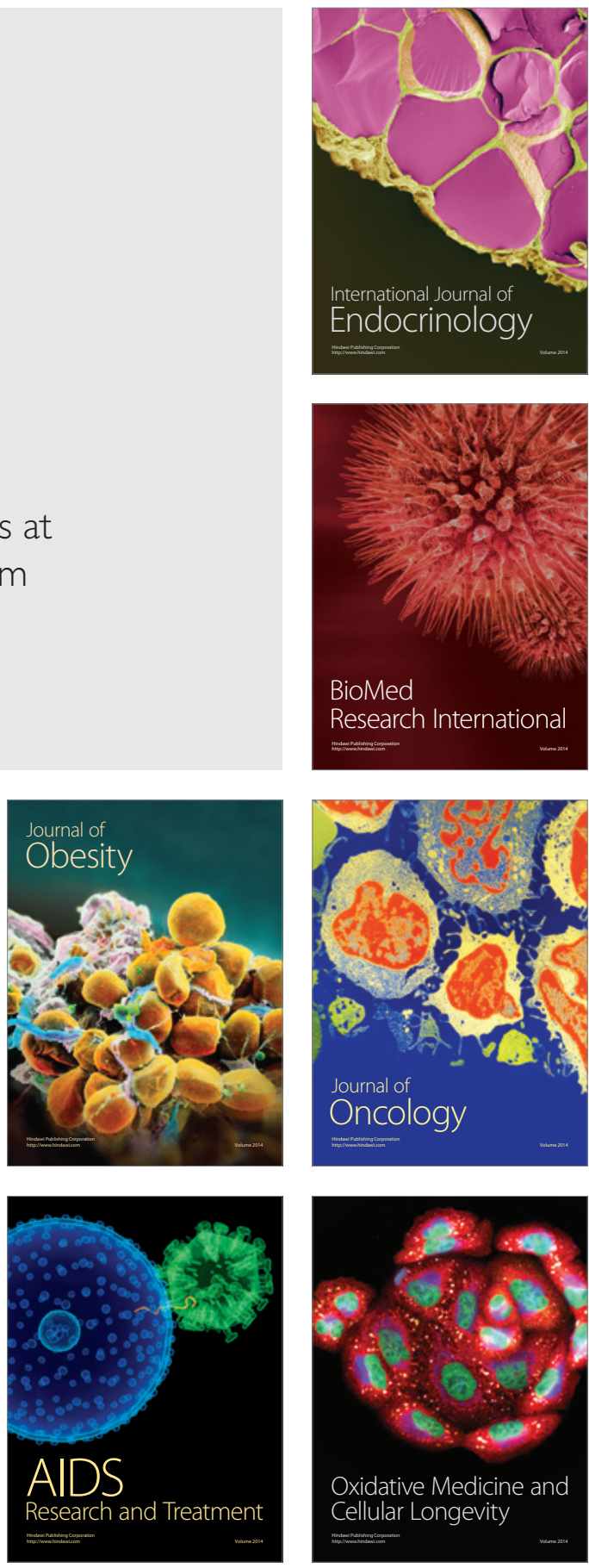